\section{Does health status explain gender dissimilarity in healthcare use among older adults?}

\author{
Estado de saúde explica a disparidade entre \\ mulheres e homens idosos no uso da assistência?
}

\author{
1 Faculdade de Medicina, \\ Universidade Federal \\ de Minas Gerais, \\ Belo Horizonte, Brasil. \\ 2 Ageing and Life Course \\ Unit, World Health \\ Organization, Geneva, \\ Switzerland. \\ 3 Gerência de Epidemiologia, \\ Secretaria Municipal \\ de Saúde de Belo Horizonte, \\ Belo Horizonte, Brasil. \\ Correspondence \\ S. M. Barreto \\ Departamento de Medicina \\ Preventiva e Social, \\ Faculdade de Medicina, \\ Universidade Federal \\ de Minas Gerais. \\ Av. Prof. Alfredo Balena 190 \\ Belo Horizonte, $M G$ \\ 30130-100, Brasil. \\ sbarreto@medicina.ufmg.br
}

\begin{abstract}
This study investigates the extent to which gender dissimilarity in healthcare use in later life is explained by variation in health and social-economic statuses. It is based on a nationwide sample in Brazil of 12,757 men and 16,186 women aged $60+$ years. Individuals with great difficulties or unable to perform at least one daily living activity and/or to walk $100 \mathrm{~m}$ were classified as "established disability". Those who had interrupted their activities in the previous 15 days because of a health problem were regarded as "temporarily disabled". The remaining we classified as "healthy". These categories were analyzed by multinomial logistic regression, taking "healthy" as the reference category. Prevalences of established disability were 6\% among men and $11 \%$ among women. Temporary disabilities were $7.9 \%$ and $10.1 \%$, respectively. Poor health status was associated with increased use of healthcare among men and women, but men and women differed significantly in relation to use pattern after adjustment for age, health status, and income. Older women were greater consumers of outpatient services and older men of inpatient care.
\end{abstract}

Health Conditions; Health Services; Aging Health; Gender
Sandhi Maria Barreto 1

Alexandre Kalache ${ }^{2}$

Luana Giatti 1,3

\section{Introduction}

There is a considerable body of evidence suggesting gender-based inequalities in access to and use of healthcare at various levels $1,2,3$. However, most studies do not present separate analysis of older people, especially in developing countries where population ageing is a more recent phenomenon. In an overwhelming majority of countries, women outnumber men in later life and this advantage cannot be accounted for by socioeconomic or ethnic factors 4 .

A previous analysis of a representative sample of Brazilians aged 60 and over identified gender differences in health service use patterns. While older women reported more outpatient visits, older men residing in urban areas (around $80 \%$ of all older men) were more likely to have been hospitalized, independently of age 5,6. Studies in developed countries also reported higher use of primary health care by elderly women 7 . However, because consulting with a doctor is itself a very strong predictor of hospitalizations among older men and women 8 , the finding of gender differentials in healthcare use seems paradoxical.

Patterns of seeking and using healthcare in later life are determined by a number of factors that affect older men and women differently. Globally, there is good evidence that older women disproportionately suffer from chronic disabling conditions, such as arthritis, that are 
not life threatening, but increase the need for heath care 9 .

Access to and use of health services are also related to socioeconomic conditions in later life. Older people, both men and women, with lower incomes exhibit worse indicators of health status and physical functioning and yet use medical services less than do those in better economic situations, independently of age $7,10,11$. A person's social economic position is a major determinant of health in adulthood and this influence persists into later life 5 . In addition, one study on the effects of socioeconomic inequalities in health by age and gender suggests that inequalities that favor affluence tend to increase with age in Brazil 12.

Poverty, low educational status and lower social support are more likely to affect older women than older men 9,13. For instance, in Brazil there are five times more older women without any source of personal income than older men, $18.6 \%$ vs. $3.5 \%$, respectively. In addition, older men's earnings are on average twice as high as those of older women 14. Brazil has a public health system that provides universal and free outpatient and hospital care. Less than $25 \%$ of the population has a private health plan 10. Even considering the extensiveness of Brazil's public health system, one cannot rule out the influence of socioeconomic circumstances in later life on men's and women's healthcare seeking behavior and use.

The objectives of this paper are to explore further possible gender differences in health status in a representative sample of older Brazilians and to examine the extent to which differences in healthcare seeking and use among elderly men and women are explained by differences in health and socioeconomic statuses.

\section{Methods}

\section{Data source}

The present study uses secondary data and was analyzed in accordance with the principles of the Declaration of Helsinki. It included all individuals aged $60+$ years that have participated in the 1998 National Household Survey (PNAD) conducted by the Instituto Brasileiro de Geografia e Estatística (IBGE - Brazilian Institute of Geography and Statistics). The survey collected data on sociodemographic factors and several aspects related to health and healthcare use. It was conducted through household interviews according to a multistage sample of the Brazilian population. The sampling stages were mu- nicipalities, areas within each selected municipality, and households within each selected area. The probability of a municipality and an area being selected depended on its population density 14 .

Income level was defined by monthly personal income. For the descriptive analysis, older individuals were divided into two groups: those receiving one Brazilian minimum wage or less per month and all the others. Other sociodemographic characteristics used in the analysis were place of residence (urban/rural), head of household (yes/no), living arrangement (alone/not alone), schooling, and per capita household income. The survey also include variables on selected reported chronic diseases and level of difficulty in performing daily living and mobility activities.

All individuals who reported great difficulties or who were not able to perform one or more daily living activities (bathing, eating, using toilet) and/or had great difficulties or were unable to walk at least $100 \mathrm{~m}$ were classified as having an "established disability". Individuals who reported having had to interrupt their routine activities in the previous 15 days because of a health problem and who had not been classified as having an established disability were regarded as "temporarily disabled". All others were regarded as "healthy". The other health indicators used in the analysis were report of one or more selected conditions: heart disease, hypertension, cancer, diabetes, bronchitis/asthma, chronic renal disease, and cirrhosis.

Access and pattern of health service use were investigated using the following variables: healthcare sought in the previous two weeks, outpatient visit(s) in previous two weeks, number of outpatient visits during prior year, hospitalisation(s) in prior year, number of hospitalisations in previous year, and private health plan coverage.

\section{Analysis}

The data were analysed using the survey procedures of Stata statistical software. A special algorithm provided by IBGE was incorporated in the analysis to account for the design effects due to the multiple stage sampling process. Initially, we examined the distribution of older people according to health status by sex and income subgroups. A multinomial logistic regression analysis was next used to identify all the factors associated with temporary and established disabilities in older men and women, separately, taking healthy persons as the refer- 
ence category. The odds ratios are presented adjusted for age and place of residence.

Finally, existing differences among older men and women in relation to healthcare use variables were then estimated with the odds ratios and confidence intervals (Woolf's methods) obtained by multiple logistic regression analysis, after considering the effects of all major confounding variables. The final analysis was carried out separately for urban and rural populations because the distribution and access to health services vary substantially according to this variable.

\section{Results}

A total of 12,757 men and 16,186 women aged $60+$ years participated in the study. Ten percent of men and $14.9 \%$ of women had established disabilities and $8.8 \%$ and $9.3 \%$, respectively, had temporary disabilities. The remaining $81.1 \%$ of men and $75.9 \%$ of women were regarded as "healthy" $\left(\chi^{2}=157.58, \mathrm{p}<0.00001\right)$.

Figure 1 shows the distribution of older people by sex and according to health status and personal income group. The proportion of older individuals with established disabilities was much higher among the lowest income group, both in men and women, but discrepancies were greatest among men $\left(\chi^{2}=14.08, p=0.0016\right.$ among low income groups and $\chi^{2}=142.30, \mathrm{p}<$ 0.00001 among high income groups).

The proportions of older men and women who reported outpatient visits and hospital admissions in the immediate previous year are presented by "health status" at the time of interview (Figure 2). In both sexes, outpatient visits were clearly more frequent among those with temporary disability $\left(\chi^{2}=1012.61, \mathrm{p}<0.00001\right.$ for men and $\chi^{2}=967.82, \mathrm{p}<0.00001$ for women), while hospital admissions were slightly more common among those with established disability $\left(\chi^{2}=775.86, \mathrm{p}<0.00001\right.$ for men and $\left(\chi^{2}=796.65, p<0.00001\right.$ for women). Independent of health status, outpatient visits were reported more often by older women and hospital admissions by older men.

The association of health status with selected health indicators and health care use variables is presented separately for men (Table 1) and women (Table 2), with adjustment for age, personal income and place of residence. Both older men and women with established and temporary disabilities reported more chronic diseases, and were more likely to have sought healthcare, to report outpatient visits in the prior two weeks, and to report greater number

\section{Figure 1}

Distribution of older Brazilian people by present health status, according to sex and personal income group, in 1998.

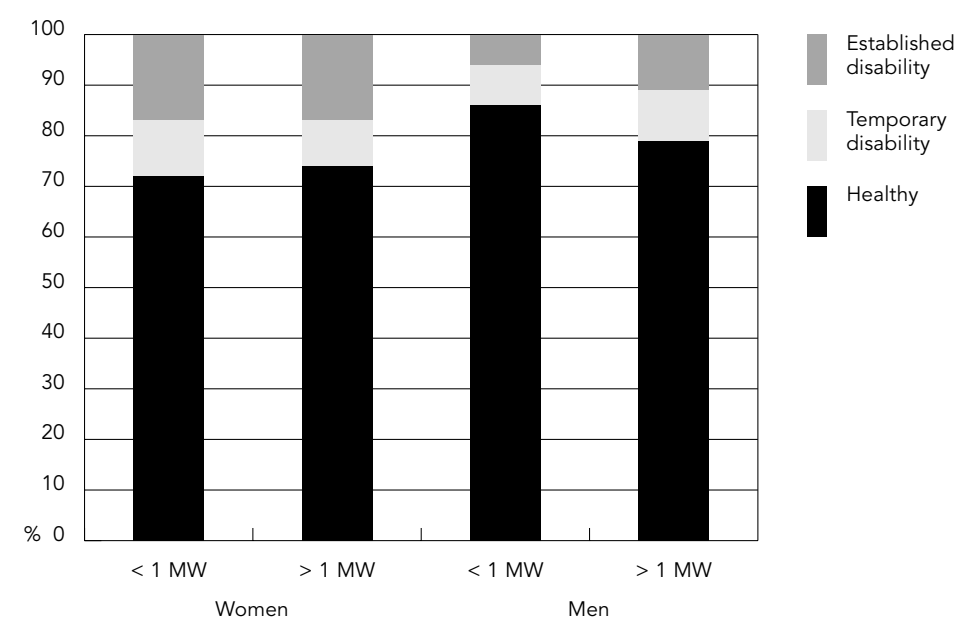

$\mathrm{MW}=$ Brazilian minimum wage.

of outpatient visits and hospitalisations in the prior year. Having a private health plan was only and negatively associated with established disability among older women.

Table 3 shows the odds ratios for older women as compared with older men in urban and rural areas in relation to all healthcare use variables after taking into account the possible confounding effects of age, personal income level, report of chronic disease, and presence of temporary or established disability. The results show that older women seek health services more often, report more outpatient visits in the previous two weeks, and greater number of outpatient visits in the previous year in urban and rural areas. However, older women living in urban areas were less likely to have been admitted to the hospital in the previous year after considering the effect of all the other factors included in the analysis.

\section{Discussion}

In agreement with other studies worldwide $15,16,17$, this study found that a greater proportion of older women than men had established and temporary disabilities. The analysis also showed that seeking and using healthcare among older individuals vary according to health status, socioeconomic factors, and sex, 
Figure 2

Proportion of older Brazilian people who attended outpatient visits and were hospitalized in the past year, by present health status and gender, in 1998.

Figure 2a

Medical visits in previous year.

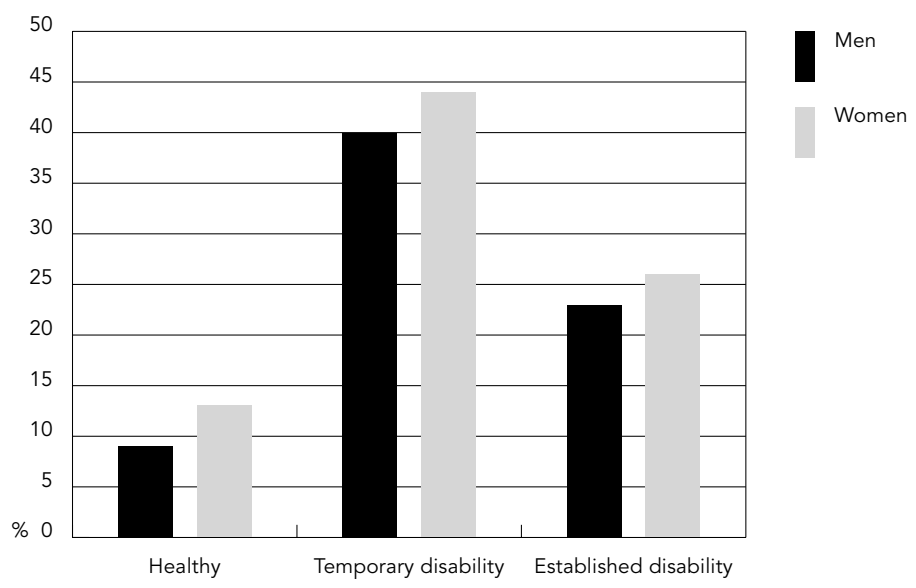

Figure $2 b$

Hospitalization rates in previous year.

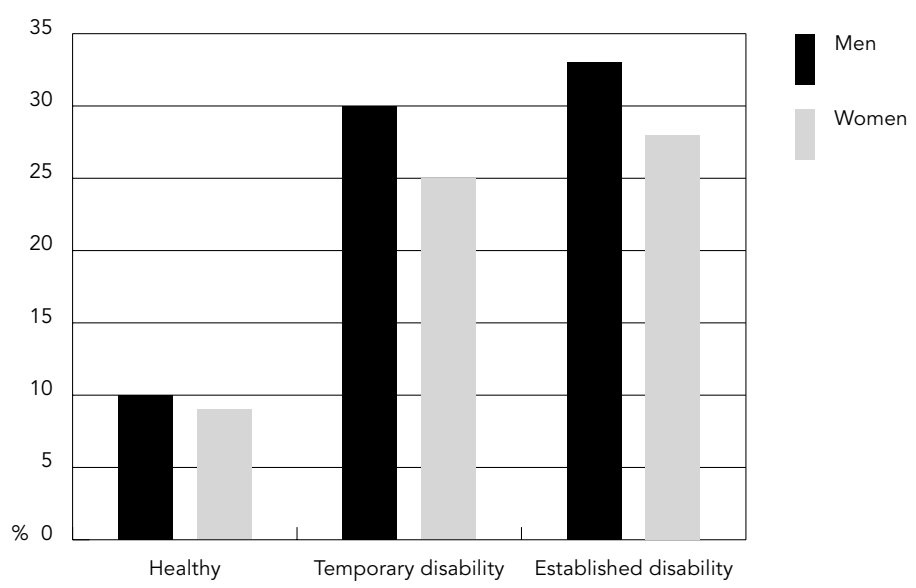

and that these three factors are all independently related to healthcare use in later life. In addition, it showed that differences in older men's and women's patterns of healthcare seeking and use could not be not explained by age, health status, or income level. Older women were greater consumers of outpatient services and older men of inpatient care.

The overall prevalence of established disability was similar and very high among poor older women and men, but older men presented a steeper inverse gradient in the age and place-adjusted odds ratios for established disability according to income levels. Such findings were also apparent in the descriptive analysis comparing income groups by sex and health status, which suggested greater discrepancies in health status among older men. A study in Taiwan found that the effect of economic difficulties was significantly stronger among older men than among older women 17 . Social class differentials in self-assessed health was also greater for older men than women in Britain 5. In the United States, poor men and men of color have the poorest indicators of health at all age groups 18 . The higher rate of chronic disabilities among low-income older men in Brazil is likely to reflect poor working conditions in adulthood as well as higher exposure to many risk factors associated with poverty, including unhealthy life-styles. Some of these risk factors, especially work-related ones, may continue to play a role in older age. In Brazil, one in four men aged $65+$ years is still engaged in the workforce, as compared with only $8 \%$ of older women 9,12 . Further investigation is necessary to clarify why poor older men are disproportionately affected by permanent disabilities in Brazil.

As expected, temporary and established disabilities were both associated with report of chronic diseases and greater use of health services among older men and women, independent of age, income, and place of residence. Although both older men and women responded to poor health status with increased health care seeking (outpatient visits and hospitalizations), the magnitudes of these effects appear to be slightly greater among older men.

However, despite the similarities concerning healthcare use in response to health needs, older men and women showed clear differences in use patterns that could not be explained by differences in health status. Analysis confirmed that independent of health, age, and income, older women report more outpatient visits and urban older men more hospital admissions. As women live longer than men, a residual con- 
Health indicators and health service use associated with health status among older men after adjustment for age, place of residence, and personal income level.

\begin{tabular}{|c|c|c|}
\hline & \multicolumn{2}{|c|}{ Health status } \\
\hline & $\begin{array}{l}\text { Temporary disability } \\
\text { Adjusted OR (95\%CI) }\end{array}$ & $\begin{array}{l}\text { Established disability } \\
\text { Adjusted OR }(95 \% \mathrm{Cl})\end{array}$ \\
\hline \multicolumn{3}{|l|}{ Chronic disease } \\
\hline No & 1.00 & 1.00 \\
\hline Yes & $3.76(3.07-4.60)$ & $3.17(2.70-3.72)$ \\
\hline \multicolumn{3}{|l|}{ Private health plan } \\
\hline No & 1.00 & 1.00 \\
\hline Yes & $0.92(0.74-1.15)$ & $1.02(0.85-1.23)$ \\
\hline \multicolumn{3}{|c|}{ Sought health services in previous 2 weeks } \\
\hline Yes. and succeeded & 1.00 & 1.00 \\
\hline Yes. but did not succeed & $1.28(0.74-2.22)$ & $0.53(0.20-1.37)$ \\
\hline Did not seek & $0.10(0.09-0.12)$ & $0.24(0.20-0.29)$ \\
\hline \multicolumn{3}{|c|}{ Outpatient visits in previous 2 weeks } \\
\hline No & 1.00 & 1.00 \\
\hline Yes & $7.33(6.23-8.61)$ & $3.41(2.80-4.16)$ \\
\hline \multicolumn{3}{|c|}{ Number of outpatient visits in previous year } \\
\hline 0 & 1.00 & 1.00 \\
\hline 1 & $2.13(1.68-2.70)$ & $1.17(0.90-1.53)$ \\
\hline 2 & $2.77(2.16-3.56)$ & $2.03(1.62-2.54)$ \\
\hline $3+$ & $5.42(4.48-6.58)$ & $4.37(3.61-5.29)$ \\
\hline \multicolumn{3}{|c|}{ Hospitalisation in previous year } \\
\hline No & 1.00 & 1.00 \\
\hline Yes & $3.90(3.37-4.51)$ & $4.40(3.79-5.12)$ \\
\hline \multicolumn{3}{|c|}{ Number of hospitalisations in previous year } \\
\hline 0 & 1.00 & 1.00 \\
\hline 1 & $3.62(3.05-4.29)$ & $3.04(2.56-3.62)$ \\
\hline $2+$ & $4.83(3.78-6.17)$ & $8.46(6.70-10.68)$ \\
\hline
\end{tabular}

OR and $95 \% \mathrm{Cl}$ obtained by multinomial logistic regression and adjusted by age, place of residence, and personal income. Reference category: "healthy".

founding by age due to age-group adjustment would tend to bias downward the observed gender differences in hospital use. Moreover, such differences are present even among healthier older men and women, as seen in Figure 2. Very similar gender differences in patterns of health services use were also observed in other studies 2,19. Two questions arise from these differences: (1) are men or women under- or overusing outpatient or inpatient services, and (2) do findings express sex differences in health care needs that were not accounted for in the present study?

The higher frequency of outpatient visits among older women, independent of health status, might be explained by: (1) differences in disease pattern, (2) women's greater compliance with medical counseling and treatment, and (3) women's greater use of regular and preventive health check-up. In relation to disease pattern, it is well known that older women have higher prevalence of health problems such as osteoarthritis, which increase healthcare utilization, especially outpatient care 20,21,22. Numerous studies on common chronic conditions, such as hypertension, also found that women have greater awareness of and tend to comply better with treatment than men 23,24,25. Additionally, very often compliance involves more regular medical visits. Even in the absence 
Health indicators and health service use associated with health status among older women after adjustment for age, place of residence, and personal income level.

\begin{tabular}{|c|c|c|}
\hline & \multicolumn{2}{|c|}{ Health status } \\
\hline & $\begin{array}{l}\text { Temporary disability } \\
\text { Adjusted OR }(95 \% \mathrm{Cl})\end{array}$ & $\begin{array}{c}\text { Chronic disability } \\
\text { Adjusted OR }(95 \% \mathrm{Cl})\end{array}$ \\
\hline \multicolumn{3}{|l|}{ Chronic disease } \\
\hline No & 1.00 & 1.00 \\
\hline Yes & $3.12(2.64-3.67)$ & $3.36(2.79-4.04)$ \\
\hline \multicolumn{3}{|c|}{ Private health plan } \\
\hline No & 1.00 & 1.00 \\
\hline Yes & $1.01(0.88-1.16)$ & $0.78(0.68-0.89)$ \\
\hline \multicolumn{3}{|c|}{ Access to health services in previous 2 weeks } \\
\hline Yes & 1.00 & 1.00 \\
\hline Not & $1.43(0.90-2.27)$ & $1.42(0.84-2.42)$ \\
\hline Did not seek & $0.15(0.13-0.17)$ & $0.38(0.34-0.42)$ \\
\hline \multicolumn{3}{|c|}{ Outpatient visits in previous 2 weeks } \\
\hline No & 1.00 & 1.00 \\
\hline Yes & $5.21(4.63-5.87)$ & $2.43(2.15-2.74)$ \\
\hline \multicolumn{3}{|c|}{ Number of outpatient visits in previous year } \\
\hline 0 & 1.00 & 1.00 \\
\hline 1 & $1.73(1.34-2.23)$ & $1.35(1.11-1.65)$ \\
\hline 2 & $2.59(2.05-3.29)$ & $1.19(0.97-1.50)$ \\
\hline $3+$ & $5.15(4.10-6.46)$ & $2.58(2.23-2.98)$ \\
\hline \multicolumn{3}{|c|}{ Hospitalisation in previous year } \\
\hline No & 1.00 & 1.00 \\
\hline Yes & $3.31(2.82-3.88)$ & $3.58(3.19-4.02)$ \\
\hline \multicolumn{3}{|c|}{ Number of hospitalisations in previous year } \\
\hline 0 & 1.00 & 1.00 \\
\hline 1 & $2.95(2.51-3.48)$ & $2.75(2.38-3.18)$ \\
\hline $2+$ & $4.33(3.18-5.88)$ & $5.91(4.72-7.40)$ \\
\hline
\end{tabular}

OR and $95 \% \mathrm{Cl}$ obtained by multinomial logistic regression and adjusted by age, place of residence, and personal income. Reference category: "healthy".

of disease, women tend to seek more health-related information than men as a result of social role differentiation 26,27 .

It is possible that, overall, men are more pessimistic than women on the health benefits of outpatient services. In a study of health perceptions regarding heart disease, arthritis, and sleep disorders, older individuals who believed that nothing could be done to improve their health or that these conditions were "normal" parts of ageing were less likely to have regular physician visits 28 . Older persons who considered health problems as normal parts of aging also had lower use rates of preventive medical services in one community based study 29 .
The reasons for higher rates of hospital admissions among older men in urban areas might be, at least in part, health-related. Many studies show that men tend to use preventive medical services less than women 27 , which could result in delays and worsening of health problems, and, in turn, increased likelihood of hospital admissions. To some extent older women's higher rates of medical appointments would prevent unnecessary hospital admissions. A randomized control trial has shown that primary care visits can reduce emergency room utilization by older adults with chronic illness ${ }^{30}$. Another possibility is that disease symptoms tend to manifest more severely in older men than women, justi- 
Access and use of health services among older women as compared with older men in urban and rural Brazil, after adjustment for potential confounding variables.

\begin{tabular}{|c|c|c|}
\hline & $\begin{array}{c}\text { Urban } \\
\text { Adjusted OR }(95 \% \mathrm{Cl})\end{array}$ & $\begin{array}{c}\text { Rural } \\
\text { Adjusted OR }(95 \% \mathrm{Cl})\end{array}$ \\
\hline \multicolumn{3}{|c|}{ Sought health services in previous 2 weeks } \\
\hline Yes, and succeeded & 1.00 & 1.00 \\
\hline Yes, but did not succeed & $1.04(0.70-1.55)$ & $1.52(0.65-3.60)$ \\
\hline Did not seek & $0.72(0.67-0.78)$ & $0.72(0.59-0.88)$ \\
\hline \multicolumn{3}{|c|}{ Outpatient visits in previous 2 weeks } \\
\hline No & 1.00 & 1.00 \\
\hline Yes & $1.37(1.27-1.49)$ & $1.39(1.12-1.72)$ \\
\hline \multicolumn{3}{|c|}{ Number of outpatient visits in previous year } \\
\hline 0 & 1.00 & 1.00 \\
\hline 1 & $1.30(1.17-1.44)$ & $1.50(1.26-1.78)$ \\
\hline 2 & $1.65(1.50-1.82)$ & $1.70(1.39-2.06)$ \\
\hline $3+$ & $2.02(1.86-2.21)$ & $2.06(1.78-2.39)$ \\
\hline \multicolumn{3}{|c|}{ Hospitalisation in previous year } \\
\hline No & 1.00 & 1.00 \\
\hline Yes & $0.77(0.71-0.84)$ & $1.09(0.91-1.30)$ \\
\hline \multicolumn{3}{|c|}{ Number of hospitalisations in previous year } \\
\hline 0 & 1.00 & 1.00 \\
\hline 1 & $0.82(0.75-0.90)$ & $1.09(0.88-1.33)$ \\
\hline $2+$ & $0.67(0.57-0.79)$ & $1.09(0.80-1.48)$ \\
\hline
\end{tabular}

OR and $95 \% \mathrm{Cl}$ obtained by multivariate logistic regression and adjusted for age, income level, report of chronic conditions, and health status. Reference category: older men.

fying men's greater need of hospital treatment. However, the findings in this study suggest that men used more hospital services independent of their health status, i.e., hospitalization rates were confirmed to be higher even among healthier older men.

There are grounds, however, to suspect gender discrimination in hospital use in urban settings. In Finland, where several important steps have been taken to achieve greater gender equity, a recent study found that women continue to receive less coronary operation than men with the same level of need 32. A British study has also identified clinically unjustified gender differences in referring rates for coronary artery bypass graft and rehabilitation ${ }^{32}$. Indeed, a number of studies on medical care needs of older people found that women with chronic angina are less likely to receive surgical treatment 33 and the best available treatment after acute myocardial infarction 34 .

In our study we found no difference in hospitalization between rural women and rural men. On average, rural women live 2.6 years less than their urban counterpart. A similar, but smaller, difference is observed among urban and rural men (one year) 35 .

As there is no difference in outpatient service use between rural men and women, it is unlikely that younger age explains the lack of gender difference in hospitalization in rural areas. It is more likely that both older men and women in rural areas have lower access to hospital care than urban elderly. This question deserves further investigation.

Unfortunately the survey does not provide data on marital status to evaluate its influence on men's and women's healthcare use in Brazil, even though the "living alone" variable may be taken as a reasonable proxy. Existing evidence suggest that marital status is an indicator of social network and seems to play an important role in health care seeking and use, especially among older men 36 . It is also possible that selfreport of disease and healthcare use varies by gender. Reporting bias is, however, more likely 
to have occurred for outpatient visits and mild diseases than for activities of daily living (used to define established disability) and hospital admissions, which are better defined and more marked factors.

In conclusion, this study identified important gender differences in health care seeking and use patterns among older adults in Brazil, which would not be explained by age, health status (a surrogate for need), or socioeconomic factors. Gender is a sociocultural construct, as is age 37 . It encompasses a broad spectrum of experiences, including a subjective evaluation attached to age and biological ageing as influenced by genetics, anxieties and exposure to environmental hazards 38 . Gender as well as sex influences health care needs, seeking, and use in later life. Knowledge of the directions of such influences can help policy makers address policies aimed at providing fair access to health care and promoting a more need-oriented use pattern among older men and women.
Resumo

O presente trabalho investiga diferenciais de gênero na condição de saúde de idosos e examina se desigualdades de gênero na utilização de serviços de saúde são explicadas pela condição de saúde ou sócio-econômica dos mesmos. Foram estudados 12.725 homens $e$ 16.186 mulheres com 60+ anos, participantes da PNAD 1998. Idosos com grande dificuldade/incapazes de realizar uma/mais atividades da vida diária elou andar mais de $100 m$ foram classificados como incapacitados, aqueles que interromperam atividades nos últimos 15 dias por problemas de saúde, como temporariamente incapacitados, e demais, como saudáveis. Utilizou-se regressão logística multinomial (referência: indivíduos saudáveis). A prevalência de homens e mulheres incapacitados foi $6 \%$ e $11 \%$, temporariamente incapacitados, 7,9\% e 10,1\% respectivamente. Pior condição de saúde está associada ao maior uso serviços de saúde, mas padrão de utilização é significativamente diferente entre ambos, independente da idade, condição de saúde ou nível de renda. Idosas apresentaram mais consulta médica, e idosos, mais internações. Identificamos diferenciais de gênero no padrão de utilização de serviços de saúde que não são explicados pela idade, condição de saúde ou sócio-econômica.

Condições de Saúde; Serviços de Saúde; Saúde do Idoso; Gênero

\section{Contributors}

S. M. Barreto é responsável pela concepção, análise e redação do trabalho. L. Giatti participou da análise e da interpretação dos resultados. A. Kalache da interpretação dos resultados e redação do trabalho.

\section{Acknowledgements}

The preliminary analysis was carried out at Centro de Pesquisas René Rachou (CPqRR - René Rachou Research Centre), Fundação Oswaldo Cruz (FIOCRUZ Oswaldo Cruz Foundation). Professors Maria Fernanda Lima-Costa and Elizabeth Uchôa, from CPqRR and Universidade Federal de Minas Gerais (UFMG Federal University of Minas Gerais), contributed in the initial phase of the study. Irene Hoskins, from Ageing and Life Course Unit/World Health Organization (ALC/ WHO), helped to interpret the final results. The final analysis and preparation of the manuscript took place in the ALC/WHO. S. M. Barreto's postdoctoral program was funded by the Brazilian Agency CAPES.

\section{References}

1. Maynard C, Litwin PE, Martin JS, Weaver WD. Gender differences in the treatment and outcome of acute myocardial infarction. Results from the Myocardial Infarction Triage and Intervention Registry. Arch Intern Med 1992; 152:972-6.

2. Fernandez E, Schiaffino A, Rajmil L, Badia X, Segura $\mathrm{A}$. Gender inequalities in health and health care services use in Catalonia (Spain). J Epidemiol Community Health 1999; 53:218-22.

3. Krumholz HM, Douglas PS, Lauer MS, Pasternak RC. Selection of patients for coronary angiography and coronary revascularization early after myocardial infarction: is there evidence for a gender bias? Ann Intern Med 1992; 116:785-90.

4. Centers of Disease Control and Prevention. Public health and aging. Trends in aging - United States and Worldwide. JAMA 2003; 289:1371-3.

5. Barreto SM, Giatti L, Kalache A. Gender inequalities in health among Brazilian older adults. Pan Am J Public Health 2004; 16:110-7. 
6. Barreto SM, Giatti L, Uchôa E, Lima-Costa MF. Gênero e desigualdade em saúde entre idosos brasileiros. In: Anais da I Oficina de Trabalho sobre Desigualdades Sociais e de Gênero em Saúde dos Idosos no Brasil. Ouro Preto: Editora UFMG; 2002. p. 59-69.

7. Arber S, Ginn J. Gender and inequalities in later life. Br J Sociol 1993; 36:33-46.

8. Mutran E, Ferraro DK. Medical need and use of services among older men and women. J Gerontol 1988; 43:S162-71.

9. World Health Organization. Women, ageing and health. Achieving health across the life span. Geneva: World Health Organization; 1998.

10. Lima-Costa MF, Barreto SM, Firmo JOA, Uchôa E. Socioeconomic position and health in a population of Brazilian elderly. The Bambui Health and Ageing Study (BHAS). Pan Am J Public Health 2003; 13:387-94.

11. Giatti L, Barreto SM. Health, work, and aging in Brazil. Cad Saúde Pública 2003; 19:759-71.

12. Diaz MD. Socio-economic health inequalities in Brazil: gender and age effects. Health Econ 2002; 11:141-54.

13. Rosenberg MW, Wilson K. Gender, poverty and location: how much difference do they make in the geography of health inequalities? Soc Sci Med 2000; 51:275-87.

14. Giatti L, Barreto SM. Women's work and health in older age. Ciênc Saúde Coletiva 2002; 7:825-39.

15. Arber S, Cooper H. Gender differences in health in later life: the new paradox? Soc Sci Med 1999; 48:61-76.

16. Prager E, Walter-Ginzburg A, Blumstein T, Modan B. Gender differences in positive and negative self-assessments of health status in a national epidemiological study of Israeli aged. J Women Aging 1999; 11:21-4.

17. Beckett M, Goldman N, Weinstein M, Lin IF, Chuang YL. Social environment, life challenge, and health among the elderly in Taiwan. Soc Sci Med 2002; 55:191-209.

18. Treadwell HM, Ro M. Poverty, race, and the invisible men. Am J Public Health 2003, 93:705-7.

19. Bertakis KD, Azari R, Helms LJ, Callahan EJ, Robbins JA. Gender differences in the utilization of health care services. J Fam Pract 2000; 49:147-52.

20. Verbrugge LM. Women, men, and osteoarthritis. Arthritis Care Res 1995; 8:212-20.

21. Mili F, Helmick CG, Zack MM. Prevalence of arthritis: analysis of data from the US Behavioral Risk Factor Surveillance System, 1996-99. J Rheumatol 2002; 29:1981-8.

22. Dunlop DD, Manheim LM, Song J, Chang RW. Health care utilization among older adults with arthitis. Arthritis Rheum 2003; 49:164-71.

23. Firmo JOA, Barreto SM, Lima-Costa MF. The Bambui Health and Aging Study (BHAS): factors associated with the treatment of hipertension in older adults in the community. Cad Saúde Pública $2003 ; 19: 817-27$
24. Hyman DJ, Pavlik VN. Characteristics of patients with uncontrolled hypertension in the United States. N Engl J Med 2001; 345:479-86.

25. Jo I, Ahn Y, Lee J, Shin KR, Lee HK, Shin C. Prevalence, awareness, treatment, control and risk factors of hypertension in Korea: the Ansan study. J Hypertens 2001; 19:1523-32.

26. Courtenay WH. Constructions of masculinity and their influence on men's well-being: a theory of gender and health. Soc Sci Med 2000; 50:1385401.

27. Liang W, Shediac-Rizkallah MC, Celentano DD, Rohde C. A population-based study of age and gender differences in patterns of health-related behaviors. Am J Prev Med 1999; 17:8-17.

28. Goodwin JS, Black SA, Satish S. Ageing versus disease: the opinions of older black, Hispanic, and non-Hispanic white Americans about the causes and treatment of common medical conditions. J Am Geriatr Soc 1999; 47:973-9.

29. Sarkisian CA, Rays RD, Mangione CM. Do older adults expect to age successfully? The association between expectations regarding aging and beleifs regarding health care seeking among older adults. J Am Geriatr Soc 2002; 50:1837-43.

30. Coleman EA, Eilertsen TB, Kramer AM, Magid DJ, Beck A, Conner D. Reducing emergency visits in older adults with chronic illness. A randomized, controlled trial of group visits. Eff Clin Pract 2001; 4:49-57.

31. Hetemaa T, Keskimaki I, Manderbacka K, Leyland $\mathrm{AH}$, Koskinen S. How did the recent increase in the supply of coronary operations in Finland affect socoeconomic and gender equity in their use? J Epidemiol Community Health 2003; 57:17885.

32. Raine RA, Black NA, Bowker TJ, Wood DA. Gender differences in management and outcome of patients with acute coronary artery disease. J Epidemiol Community Health 2002; 56:791-7.

33. Petticrew M, McKee M, Jones J. Coronary artery surgery: are women discriminated against? BMJ 1993; 306:1164-6.

34. Clarke KW, Gray D, Keating NA, Hampton JR. Do women with acute myocardial infarction receive the same treatment as men? BMJ 1994; 309:563-6.

35. Beltrão KI, Camarano AA, Kanso S. Dinâmica populacional brasileira na virada do século XX. Rio de Janeiro: Instituto de Pesquisa Econômica Aplicada; 2004. (Texto para Discussão 1.034).

36. Gallant MP, Dorn GP. Gender and race differences in the predictors of daily health practices among older adults. Health Educ Res 2001; 16:21-31.

37. World Health Organization. Men, ageing and health. Achieving health across the life span. Geneva: World Health Organization; 2001.

38. Moynihan C. Men, women, gender and cancer. Eur J Cancer Care 2002; 11:166-72.

Submitted on 27/Jan/2005

Final version resubmitted on 17/Jun/2005

Approved on 20/Jul/2005 